\title{
Fatigue Life Prediction of Rolling Bearings Based on Modified SWT Mean Stress Correction
}

\author{
Aodi Yu ${ }^{1}$, Hong-Zhong Huang ${ }^{1,2^{*}}$, Yan-Feng $\mathrm{Li}^{1,2}, \mathrm{He} \mathrm{Li}^{1}$ and Ying Zeng ${ }^{1}$
}

\begin{abstract}
The existing engineering empirical life analysis models are not capable of considering the constitutive behavior of materials under contact loads; as a consequence, these methods may not be accurate to predict fatigue lives of rolling bearings. In addition, the contact stress of bearing in operation is cyclically pulsating, it also means that the bearing undergo non-symmetrical fatigue loadings. Since the mean stress has great effects on fatigue life, in this work, a novel fatigue life prediction model based on the modified SWT mean stress correction is proposed as a basis of which to estimate the fatigue life of rolling bearings, in which, takes sensitivity of materials and mean stress into account. A compensation factor is introduced to overcome the inaccurate predictions resulted from the Smith, Watson, and Topper (SWT) model that considers the mean stress effect and sensitivity while assuming the sensitivity coefficient of all materials to be 0.5 . Moreover, the validation of the model is finalized by several practical experimental data and the comparison to the conventional SWT model. The results show the better performance of the proposed model, especially in the accuracy than the existing SWT model. This research will shed light on a new direction for predicting the fatigue life of rolling bearings.
\end{abstract}

Keywords: Rolling bearings, Fatigue life prediction, Modified SWT model, Mean stress correction

\section{Introduction}

Complicated rotational machines and systems like machine tools [1, 2], wind turbines [3, 4], and robots [5, 6] having emerged during the last several decades. Rolling bearings are basic parts of such equipment and systems. Today's complicated rotational machines and systems require rolling bearings work in harsh conditions, such as heavy load, high speed and high temperature, which brings about challenges to several crucial performances of rolling bearings like reliability and service life.

The fatigue life models of rolling bearings can be divided into three categories: engineering models, condition monitoring based models, and theoretical models. Engineering models including, not limited to, LundbergPalmgren (L-P) model, Ioannides-Harris (I-H) model, and Zaretsky model [7-10]. Currently, condition

\footnotetext{
*Correspondence: hzhuang@uestc.edu.cn

${ }^{1}$ School of Mechanical and Electrical Engineering, University of Electronic

Science and Technology of China, Chengdu 611731, China

Full list of author information is available at the end of the article
}

monitoring-based life predictions tend to be a hot topic. For instance, Yakout [11] predicted the fatigue life of rolling elements according to vibration data. Wang et al. [12] proposed mixed effects models for fault prognostics of rolling element bearings. The models are able to simultaneously model different degradation process phases of rolling bearings. Cui et al. [13] established a Switching Unscented Kalman Filter (SKF) method for remaining useful life prediction of rolling bearings, and the effectiveness of the method is shown by comparing with the traditional SKF algorithm. Ahmad et al. [14] introduced a reliable technique for the health prognosis of rolling element bearings, which infers a bearing's health state through a dimensionless health indicator (HI) and estimates its remaining useful life (RUL) using dynamic regression models. Wang et al. [15] proposed a life prediction method for industrial rolling bearings based on state recognition and similarity analysis, which provides some theoretical guidance and basis for the safe operation and maintenance of rolling bearings. 
The mentioned models are mainly based on artificial intelligence techniques and statistical regression methods, and those require sufficient experimental data for model training. Furthermore, the above methods cannot describe the failure mechanism in the process of contact fatigue failure well. Accordingly, theoretical models based on the principles of mechanics are proposed. Warda et al. [16] introduced a fatigue life prediction method of radial cylindrical roller bearings, in which the influence of bearing geometric parameters were considered. Shi et al. [17] presented a relative fatigue life calculation method considering surface texture on high-speed and heavy-load ball bearing. Yang et al. [18] discussed the mechanical properties of double-row tapered roller bearings through expanding the mathematical model of three degrees of freedom, and analysed the contact load and fatigue life of bearings under different loads. Quagliato et al. [19] predicted the life of roller bearings by accelerated testing, and finite element (FE) models, was developed for crossed and tapered roller bearings. He et al. [20, 21] proposed a method to test the accelerated fatigue life using a small sample test, which provides an experimental reference for bearing design, and also provides the foundation for studies of the fatigue failure mechanisms of raceways.

Rolling bearings are subjected to alternating loads during operation. The load amplitude and mean stress continuously change with different working conditions. It is a consensus that the mean stress indeed affects the fatigue life of rolling bearings [22-27]. For instance, Barbosa et al. [28] proposed an artificial neural network method considering the influence of mean stress on the fatigue life of metallic materials, which can estimate the safety region for high-cycle fatigue regimes. Zhang et al. [29] analyzed the influence of mean stress and phase angle on multiaxial fatigue behavior of TiAl alloy and established a life model with multiple loading variables, and the proposed method is of good accuracy compared with Matake method and McDiarmid method. Benedetti et al. [30] developed a new fatigue criterion based on strainenergy-density (SED) to illustrate the influence of mean stress and plasticity on the uniaxial fatigue strength. Kalombo et al. [31] used an artificial neural network to predict the fatigue life of an all-aluminum alloy 1055 MCM conductor, in which mean stresses are modeled. Li et al. [32] established a new fatigue model based on the effect of mean stress on high-cycle fatigue performance; the proposed model's prediction is closer to fatigue test data via comparing with Goodman, Gerber, Morrow, Soderberg, and Elliptic (ASME) models. Laszlo et al. [33] introduced a numerical fatigue assessment method for composite plates, which considered mean stress correction and multiaxial fatigue failure criterion inspection. Duan et al. [34] presented a fatigue life prediction method considering shrinkage cavity, secondary dendrite arm spacing (SDAS), and mean stress, which lays a solid foundation of the optimization design and lightweight design of aluminum alloy wheels. Rolling contact fatigue is a common failure mode of rolling bearings [35, 36]. The contact load and stress at each contact point of the bearing are cyclically pulsating and belong to asymmetric cyclic load. Therefore, the influence of mean stress needs to be considered when predicting the contact fatigue life of rolling bearings. Compared with the above mean stress correction models, the SWT model with a simple form and does not require additional material parameters. Moreover, it can reflect the sensitivity of the material. Hence, in this paper, we attempt to consider the sensitivity of different materials to mean stress and propose a modified life prediction model based on the SWT correction.

The rest of this paper is organized as follows. Section 2 proposes a life prediction model based on modified SWT correction that considers the mean stress effect and sensitivity. Section 3 develops the fatigue life prediction model of rolling bearings. Section 4 performs model validation using the experimental data of GH4133, $1 \mathrm{Cr} 11 \mathrm{Ni}$ $2 \mathrm{~W} 2 \mathrm{MoV}$, and $\mathrm{GCr} 15$, and verifies the applicability of the proposed model. In Section 5, conclusions are drawn.

\section{Modified Fatigue Life Prediction Model Based on Mean Stress Correction}

\subsection{Stress-life Based Prediction Methods}

The fatigue life of rolling bearings can be evaluated using stress-life prediction methods that are theoretically based on S-N curve. The stress-life prediction method can be expressed by the Basquin formula, as:

$$
\sigma N_{f}^{-b}=A,
$$

where $N_{f}$ represents fatigue life, $A$ denotes the fatigue strength constant, which is an inherent property of the material, $b$ is the material constant.

The specimen can withstand countless stress cycles without breaking under stress lower than a certain critical stress amplitude, and the fatigue life tends to be infinite. However, the Basquin formula fails to reflect the fatigue limit and its influence on fatigue. The full stressfatigue life curve is shown in Figure 1. Considering the influence of the fatigue limit, the relationship between fatigue life, fatigue limit stress and stress range is established by Weibull [37], as:

$$
N_{f}=C_{f}\left(\sigma_{a}-\sigma_{a c}\right)^{\beta},
$$

where $\sigma_{a c}$ is the endurance-limit stress, $C_{f}$ and $\beta$ are material constants determined by experiments. 


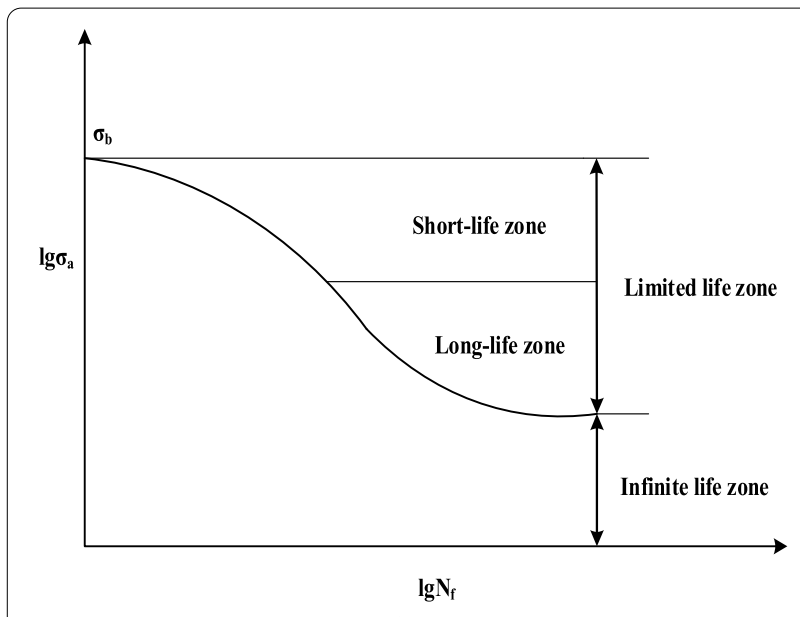

Figure 1 The full stress-fatigue life curve

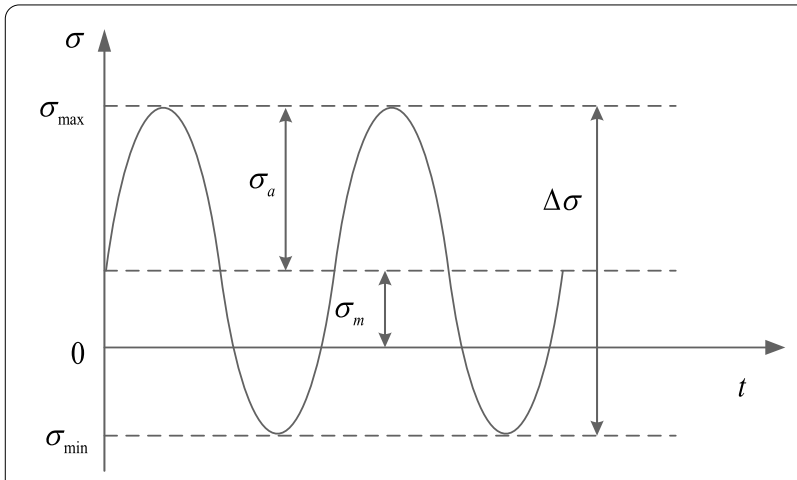

Figure 2 The asymmetric cyclic load

Rolling bearings are subject to asymmetric cyclic loads during operation, see Figure 2. The load amplitude and mean stress are decisive factors of the fatigue life of rolling bearings. It should be pointed out that the Weibull formula is able to fit the fatigue life test results under a certain stress ratio or mean stress and not functioning in showing the effect of stress ratio or mean stress on fatigue life.

Walker correction reflects the mean stress sensitivity of materials by introducing the mean stress sensitivity coefficient $\gamma$, which can effectively improve the prediction accuracy [38], see Eq. (3). Moreover, Smith, Watson, and Topper [39] put forward a simple form of mean stress correction see Eq. (4) and which is used to modify Weibull formula to obtain the fatigue life prediction model considering the mean stress effect, see Eq. (5), as:

$$
\sigma_{a r}=\sigma_{\max }^{1-\gamma} \sigma_{a}^{\gamma}=\sigma_{\max }\left(\frac{1-R}{2}\right)^{\gamma},
$$

$$
\begin{aligned}
& \sigma_{a r}=\sqrt{\sigma_{\max } \sigma_{a}}=\sigma_{\max } \sqrt{\frac{1-R}{2}} \\
& N_{f}=C_{0}\left(\sigma_{a r}-\sigma_{a c}\right)^{\beta_{0}}=C_{0}\left(\sigma_{\max } \sqrt{\frac{1-R}{2}}-\sigma_{a c}\right)^{\beta_{0}},
\end{aligned}
$$

where $\sigma_{a r}$ is the equivalent stress amplitude, $\sigma_{\max }$ is maximum stress, $\sigma_{a}$ is stress amplitude, $R$ denotes stress ratio. $\gamma$ denotes the mean stress sensitivity coefficient, and its value is between [0 1], the larger $\gamma$, the less sensitive the material to mean stress, and vice versa. $C_{0}$ and $\beta_{0}$ are material constants.

\subsection{The Proposed Model}

SWT correction is a special form of Walker correction, and it determines the sensitivity of different materials to the mean stress to be 0.5 , that is $\gamma=0.5$. Dowling [40] found that $\gamma$ is related to fatigue performance parameter yield limit of materials through a large number of fatigue tests of metal materials (alloys and steels), in detail, $\gamma$ decreases as the yield limit increases. A compensation factor $\alpha$ is introduced to consider the sensitivity of the material to the mean stress. Substituting $\alpha$ into Eq. (5), a modified fatigue life prediction model based on SWT criterion is proposed, as:

$$
\begin{aligned}
& N_{f}=C_{1}\left(\alpha \sigma_{\max } \sqrt{\frac{1-R}{2}}-\sigma_{a c}\right)^{\beta_{1}}, \\
& \alpha=\frac{2 \sigma_{b}}{\sigma_{b}+\sigma_{0}},
\end{aligned}
$$

where $C_{1}$ and $\beta_{1}$ are material constants. $\sigma_{b}$ indicates the yield limit, $\sigma_{0}$ represents the yield limit of similar materials when $\gamma=0.5$.

\section{Fatigue Life Prediction of Rolling Bearings Based on the Proposed Model}

\subsection{Load and Stress Distribution of Rolling Bearings}

The main performance parameters of rolling bearings, including deformation, contact stress between rolling elements and rings, stiffness, and fatigue life, can only be calculated after the load distribution has been determined.

The load acting on the bearing is transmitted from one ring to the other through the rolling elements, so the bearing capacity is determined by the rolling element load. The rolling bearing under the action of radial load is shown in Figure 3. The load distribution of the rolling elements can be computed as [41]: 


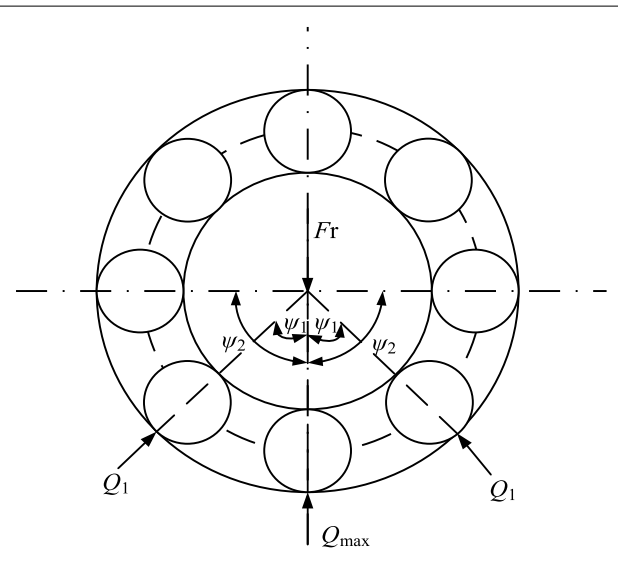

Figure 3 Force distribution of rolling bearings under the radial load

$$
Q_{\psi}=Q_{\max }\left[1-\frac{1}{2 T}(1-\cos \psi)\right]^{1.5},
$$

where $\Psi$ denotes angular position, $Q_{\Psi}$ is the rolling element load at an angle $\Psi . Q_{\max }$ is the maximum rolling element load, and $T$ demonstrates the load zone parameter.

According to the force balance rule:

$$
\begin{gathered}
F_{r}=\Sigma Q_{\psi} \cos \psi \\
=Z Q_{\max } \frac{\Sigma\left[1-\frac{1}{2 T}(1-\cos \psi)\right]^{1.5} \cos \psi}{Z} .
\end{gathered}
$$

The load distribution integral $J_{r}$ is introduced, as:

$$
\begin{gathered}
J_{r}=\frac{1}{2 \pi} \int_{-\psi_{0}}^{+\psi_{0}}\left[1-\frac{1}{2 T}(1-\cos \psi)\right]^{1.5} \cos \psi \mathrm{d} \psi \\
\approx \frac{\Sigma\left[1-\frac{1}{2 T}(1-\cos \psi)\right]^{1.5} \cos \psi}{Z} .
\end{gathered}
$$

Then,

$$
Q_{\max }=\frac{F_{r}}{Z J_{r}},
$$

where $Z$ demonstrates the number of rolling elements. $\Psi_{0}$ denotes the bearing range and $\cos \Psi_{0}=1-2 T$.

When the bearing rotates at a low speed, the influence of centrifugal force $F_{c}$ is small and can be ignored. At this time, the contact load $Q_{i j}$ and $Q_{o j}$ are equal. Conversely, the radial force balance equation of the rolling element considering the centrifugal force $F_{c}$ can be expressed as:

$$
Q_{o j}-Q_{i j}-F_{c}=0,
$$

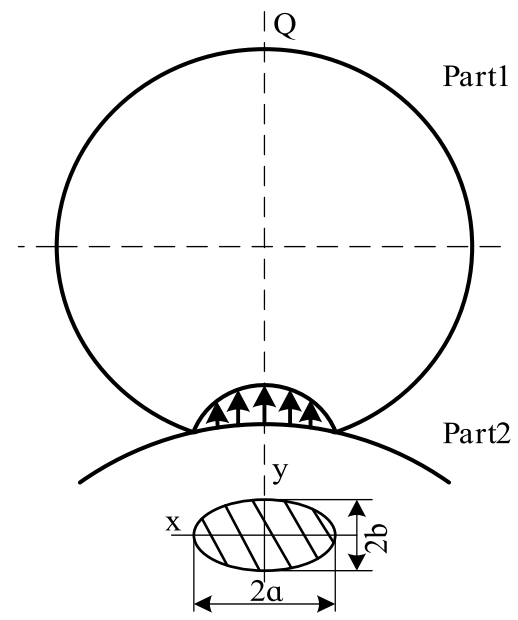

Figure 4 Contact ellipse

$$
F_{c}=\frac{\pi}{12} \rho D_{b}^{3} D_{m} \omega_{b}^{2}
$$

where $Q_{i j}$ and $Q_{o j}$ represent the contact load between the inner ring and the rolling elements we well as between the outer ring and the rolling elements. $D_{m}$ is the bearing circle diameter, $D_{b}$ is the rolling element diameter, $\rho$ denotes the density of the rolling elements, $\omega_{b}$ denotes the revolution angular velocity of the rolling element.

For a bearing, when two curved objects are pressed against each other under a load, a certain contact zone is generated at the contact point. Since the rolling contact between the raceway and rolling elements is a curved body, the Hertz elastomer contact theory can be used to calculate the contact stress and deformation in the rolling bearing.

For a ball bearing, the contact zone between a ball and a raceway is elliptical, according to the Hertz contact theory. The semi-major axis of the ellipse is represented by $a$, and the semi-minor axis is represented by $b$, as shown in Figure 4 . The contact stress in the contact zone is distributed as an ellipsoid, see Figure 5. For a contact load $Q$, the contact stress at any point $(x, y)$ in the contact zone can be expressed as follows [42]:

$$
\sigma=\frac{3 Q}{2 \pi a b}\left[1-\left(\frac{x}{a}\right)^{2}-\left(\frac{y}{b}\right)^{2}\right]^{1 / 2} .
$$

The basic equations for calculating the contact stress are derived by the Hertz contact theory, as:

$$
a=\mu \sqrt[3]{\frac{3}{E}\left(1-\lambda^{2}\right) \frac{Q}{\sum \rho}},
$$




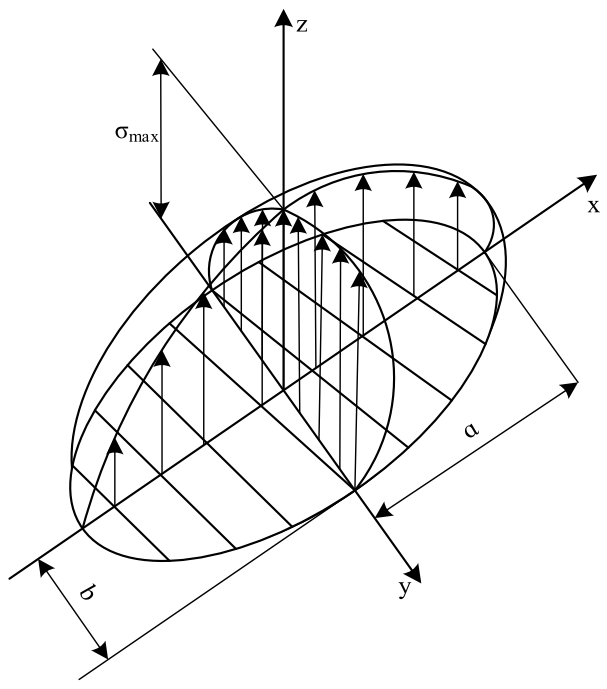

Figure 5 Stress distribution in the contact zone

$$
\begin{aligned}
& b=v \sqrt[3]{\frac{3}{E}\left(1-\lambda^{2}\right) \frac{Q}{\sum \rho}}, \\
& \sigma_{\max }=\frac{3 Q}{2 \pi a b},
\end{aligned}
$$

where $\sigma_{\max }$ represents the maximum contact stress, $\mu$ and $v$ are elliptic integrals related to the curvature function $F(\rho), E$ and $\lambda$ are the elastic modulus and Poisson's ratio of the material, respectively, and $Q$ denotes the rolling element load. $\Sigma \rho$ demonstrates the sum of the principal curvatures at the contact.

\subsection{Fatigue Life Prediction Model of Rolling Bearings}

The life prediction model proposed by Lundberg and Palmgren (L-P model) is used to predict the fatigue life of rolling bearings. But it cannot take the microstructure of the material into account, which restricts the universality of the model. However, it should be pointed out that the fatigue life prediction method proposed in this paper is based on the S-N curve of the material, which can describe the fatigue characteristics of the material well.

The number of stress cycles computed by Eq. (6) refers to the number of times that a certain point on the raceway of a bearing is subject to stress within a certain number of rotations. The contact load and stress of ring and rolling elements change when elements pass through different points in the load zone. The contact load and stress distribution at each point of the rotating ring are shown in Figure 6. The load and stress of each point of the stationary ring are unequal, and the contact load and stress at each load point show the same characteristics of pulsation cycle,

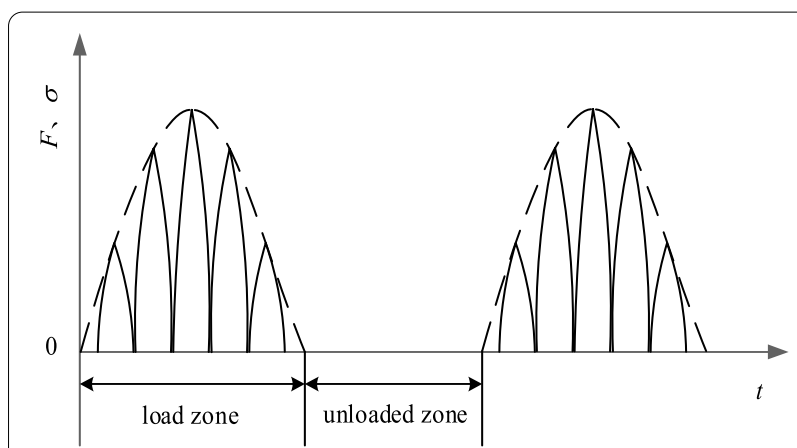

Figure 6 Contact load and stress distributions at each point of the rotating ring

but the amplitude values are different. The contact load and stress distribution at each point of the stationary ring are shown in Figure 7.

According to the contact stress distribution and the proposed modified model, the life (stress cycle number) of a bearing corresponding to each contact point can be calculated. The life unit of a rolling bearing is expressed in revolutions; hence, the number of stress cycles needs to be converted into revolutions.

When the inner ring rotates and the outer ring is stationary. Under the radial load, the contact stress of the outer ring raceway is the largest at the $0^{\circ}$ angular position of the load zone, which is the place where the outer ring is most likely to fail. The number of stress cycles and the life of the outer ring at this point can be expressed as Eq. (17). The amplitude of the stress on a point on the inner ring raceway is periodically changing due to the rotation of the inner ring. According to Miner's damage accumulation theory, when the inner ring rotates for one revolution, the damage to the inner ring can be expressed as Eq. (18), and the life of the inner ring can be expressed as Eq. (19):

$$
L_{e}=\frac{N_{e}}{u_{e}},
$$

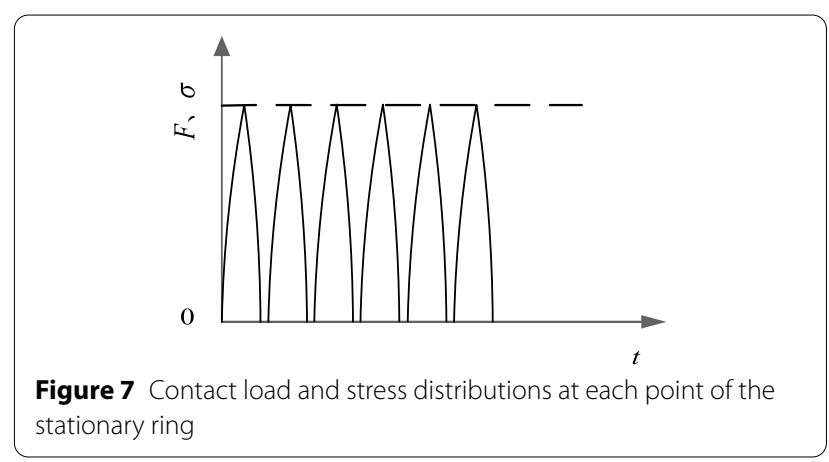




$$
\begin{aligned}
& D=\sum_{j=1}^{u_{i}} \frac{1}{N_{i j}}, \\
& L_{i}=\frac{1}{D}=\frac{1}{\sum_{j=1}^{u_{i}} \frac{1}{N_{i j}}},
\end{aligned}
$$

where $L_{i}$ and $L_{e}$ represent the life of the inner ring and outer ring, respectively. $N_{e}$ denotes the number of stress cycles at the maximum stress position on the outer raceway, and $N_{i j}$ denotes the number of stress cycles of the inner raceway under the contact stress $\sigma_{j} \cdot u_{i}$ and $u_{e}$ are the numbers of rolling elements passing through a certain point of the inner and outer rings when the inner ring rotates one revolution, which need to be obtained through the analysis of the kinematic characteristics of the bearing.

For a ball bearing with an outer ring speed of $n_{e}$ and an inner ring speed of $n_{i}$, the contact angle is zero under pure radial force. When the cage rotates once concerning the inner or outer ring, $Z$ rolling elements are passing through a certain point of the inner or outer ring. $u_{i}$ and $u_{e}$ can be expressed as Eq. (20) and Eq. (21), respectively.

$$
\begin{aligned}
& u_{i}=\frac{Z n_{c i}}{n_{i}}, \\
& u_{e}=\frac{Z n_{e c}}{n_{i}},
\end{aligned}
$$

where $n_{c i}$ denotes the rotation speed of the cage relative to the inner ring, see Eqs. (22) and (23). $n_{e c}$ denotes the rotation speed of the outer ring relative to the cage [43], see Eq. (24):

$$
\begin{aligned}
& n_{c}=\frac{1}{2}\left[n_{i}\left(1-\frac{D_{b}}{D_{m}}\right)+n_{e}\left(1+\frac{D_{b}}{D_{m}}\right)\right], \\
& n_{c i}=n_{c}-n_{i}=\frac{1}{2}\left(n_{e}-n_{i}\right)\left(1+\frac{D_{b}}{D_{m}}\right), \\
& n_{e c}=n_{e}-n_{c}=\frac{1}{2}\left(n_{e}-n_{i}\right)\left(1-\frac{D_{b}}{D_{m}}\right),
\end{aligned}
$$

where $n_{c}$ is the rotation speed of the center of rolling element. $D_{b}$ is the diameter of the rolling element, and $D_{m}$ is the mean diameter of the bearing.

Substituting Eqs. (20)-(24) into Eqs. (17)-(19), the fatigue life of the inner and outer rings of a rolling bearing can be obtained. Then, the overall life of ball bearing is computed by Eq. (25):
Table 1 Material properties of GH4133, 1Cr11Ni2W2MoV, and GCr15

\begin{tabular}{lllll}
\hline Material & $\begin{array}{l}\boldsymbol{E} \\
(\mathrm{GPa})\end{array}$ & $\begin{array}{l}\text { Poisson's } \\
\text { ratio }\end{array}$ & $\begin{array}{l}\boldsymbol{\sigma}_{\boldsymbol{b}} \\
(\mathbf{M P a})\end{array}$ & $\begin{array}{l}\text { Density } \\
\mathbf{( g / \mathbf { c m } ^ { \mathbf { 3 } } )}\end{array}$ \\
\hline GH4133 & 223 & 0.36 & 878 & 8.21 \\
1Cr11Ni2W2MoV & 180 & 0.277 & 979 & 7.8 \\
GCr15 & 207 & 0.3 & 1617 & 7.81 \\
\hline
\end{tabular}

Table 2 Experimental data for $\mathrm{GH} 4133$ at $R=0.44$

\begin{tabular}{ll}
\hline $\boldsymbol{\sigma}_{\max }(\mathrm{MPa})$ & $\boldsymbol{N t}$ (cycles) \\
\hline 935 & 2535 \\
933 & 2191 \\
905 & 3026 \\
905 & 2930 \\
887 & 2508 \\
865 & 2879 \\
863 & 3720 \\
862 & 4276 \\
841 & 5320 \\
806 & 5610 \\
777 & 8461 \\
756 & 17710 \\
749 & 12855 \\
744 & 12141 \\
741 & 14352 \\
\hline
\end{tabular}

$$
L=\left[\left(L_{i}\right)^{-10 / 9}+\left(L_{e}\right)^{-10 / 9}\right]^{-9 / 10} .
$$

\section{Case Study \\ 4.1 Validation of Modified Fatigue Life Prediction Model Based on SWT Correction}

In this section, fatigue experimental data of materials GH4133, 1Cr11Ni2W2MoV, and GCr15 under different stress ratios are employed. GH4133 is a kind of alloy with high strength as well as good thermal stability and corrosion resistance. It is often used to manufacture turbine blades, turbine disks, and other aero-engine components. $1 \mathrm{Cr} 11 \mathrm{Ni} 2 \mathrm{~W} 2 \mathrm{MoV}$ is a kind of steel with good mechanical properties and has been widely used to manufacture engine discs and shafts that work below $600{ }^{\circ} \mathrm{C}$. $\mathrm{GCr} 15$ is a high-carbon chromium bearing steel, which is a common material of rolling bearings. The properties of GH41331, Cr11Ni2W2MoV, and GCr15 are provided in Table 1. The life experimental data of GH4133 under $R=0.44$ are listed in Table 2 [44]. Table 3 shows the life experimental data of $1 \mathrm{Cr} 11 \mathrm{Ni} 2 \mathrm{~W} 2 \mathrm{MoV}$ under the condition of $R=-1$ [44]. Tables 4 and 5 respectively show the life data of the contact fatigue test at $R=0$ and the life 
Table 3 Experimental data for $1 \mathrm{Cr} 11 \mathrm{Ni} 2 \mathrm{~W} 2 \mathrm{MoV}$ at $R=-1$

\begin{tabular}{ll}
\hline $\boldsymbol{\sigma}_{\max }(\mathrm{MPa})$ & $\boldsymbol{N t}$ (cycles) \\
\hline 1183 & 2590 \\
1083 & 2912 \\
987 & 4078 \\
919 & 9402 \\
839 & 23440 \\
817 & 26124 \\
\hline
\end{tabular}

Table 4 Contact fatigue experimental data for GCr15 at $R=0$

\begin{tabular}{ll}
\hline$\sigma_{\max }(\mathrm{MPa})$ & $\boldsymbol{N t}$ (cycles) \\
\hline 5000 & $1.7629 \times 10^{7}$ \\
5300 & $1.2790 \times 10^{7}$ \\
5600 & $1.1836 \times 10^{7}$ \\
5900 & $0.8910 \times 10^{7}$ \\
6200 & $0.3655 \times 10^{7}$
\end{tabular}

Table 5 Torsion experimental data for GCr15 at $R=-1$

\begin{tabular}{ll}
\hline$\sigma_{\max }(\mathrm{MPa})$ & $\boldsymbol{N t}$ (cycles) \\
\hline 500 & $6.62 \times 10^{6}$ \\
630 & $1.09 \times 10^{6}$ \\
760 & $3.08 \times 10^{5}$ \\
800 & $3.11 \times 10^{5}$ \\
950 & $5.2 \times 10^{4}$ \\
1000 & $3.78 \times 10^{4}$ \\
\hline
\end{tabular}

data of the torsion fatigue test at $R=-1$ of GCr15 [45, 46].

The fatigue life of the three materials is calculated using the proposed model. In the meantime, the predicted life of the materials under the corresponding stress ratio conditions are also calculated using SWT model for comparison. The correlations of the materials' tested lives and predicted lives derived from different models are shown in the Figures 8, 9, 10 and 11, respectively.

In the figures, the solid black line indicates that the tested lives are exactly the same as the predicted lives. The red dashed lines indicate a life factor of \pm 2 to the tested lives. The closer predicted lives to the solid black line indicates the more accurate result.

From Figure 8, it is found that, for GH4133, nearly all predicted lives of the proposed model are within the \pm 2 scatter band, but the results predicted by the proposed model are obviously closer to the solid black line. This suggests that in comparison to SWT model, the

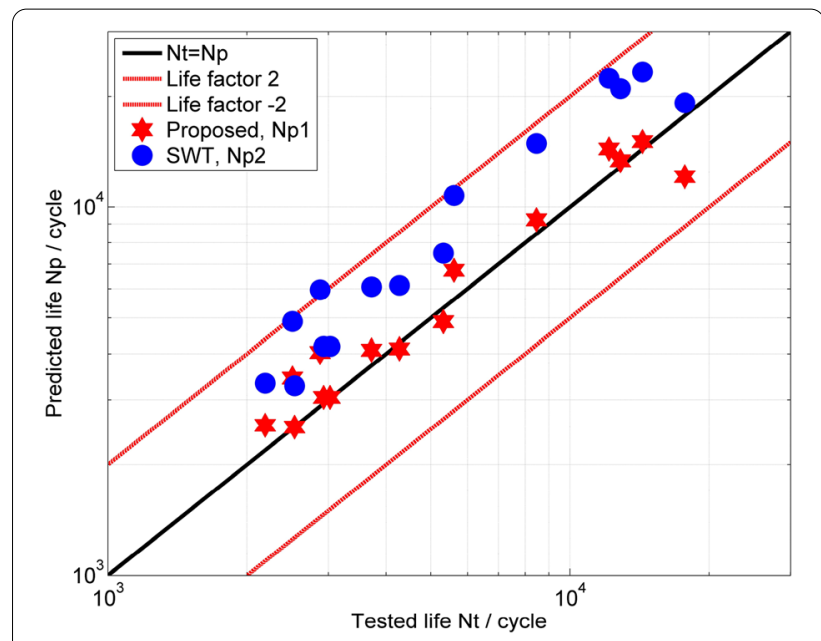

Figure 8 Predicted lives vs. tested lives of GH4133

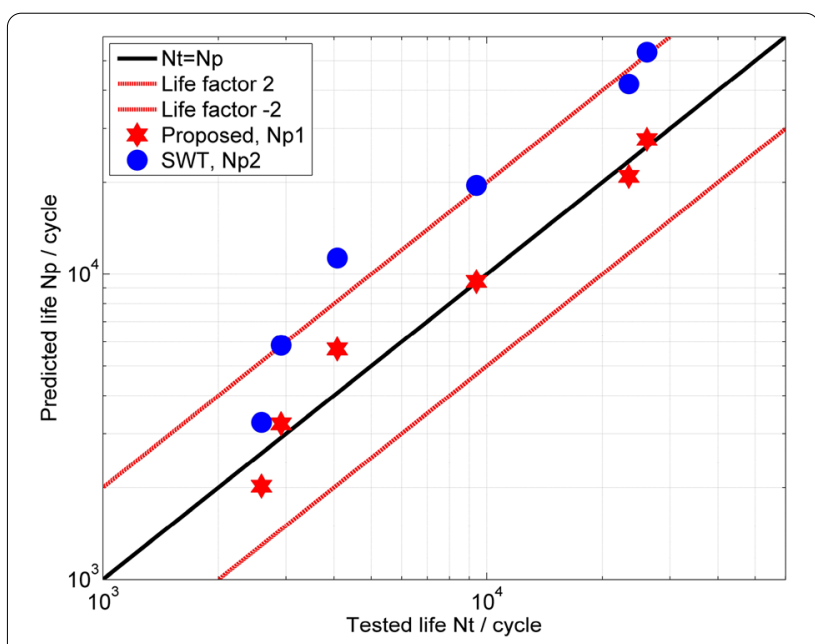

Figure 9 Predicted lives vs. the tested lives of $1 \mathrm{Cr} 11 \mathrm{Ni} 2 \mathrm{~W} 2 \mathrm{MoV}$

proposed model is more reliable and accurate in predicting the fatigue life of the alloys.

From Figure 9, it is found that for $1 \mathrm{Cr} 11 \mathrm{Ni} 2 \mathrm{~W} 2 \mathrm{MoV}$, it can be clearly observed that the prediction results of the proposed model are more consistent with test data than that of the SWT model. All predicted lives of the proposed model fall within a life factor of \pm 2 to the tested lives, which can be compared with that some predictions of the SWT model exceed the life factor of \pm 2 . Similar conclusions are true to the GCr15, see in Figures 10 and 11.

In order to better demonstrate the advantages of the proposed model in predicting the fatigue life of materials, the predicted life deviation between the logarithmic predicted life and experimental life is used to describe the prediction error, see Eq. (26) [47, 48]. In detail, the 


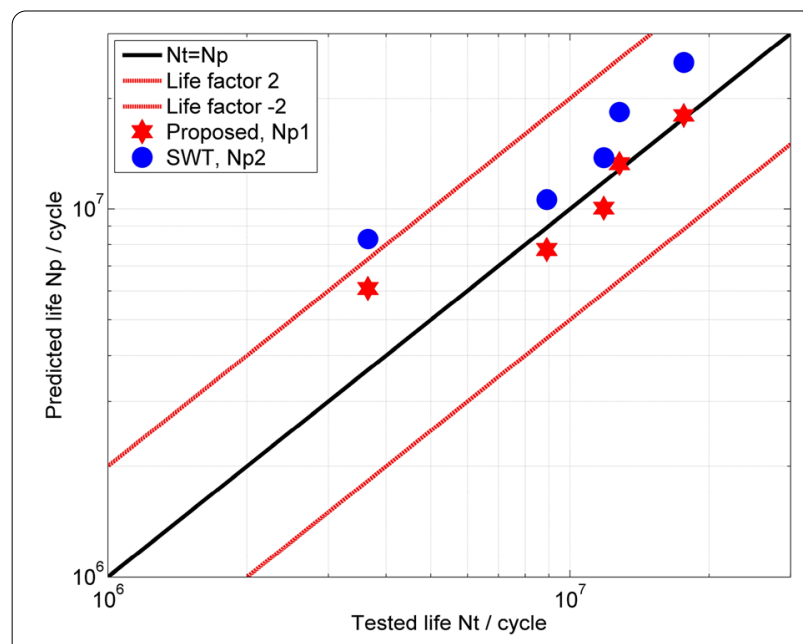

Figure 10 Predicted lives vs. tested lives of $\mathrm{GCr} 15$ at contact test

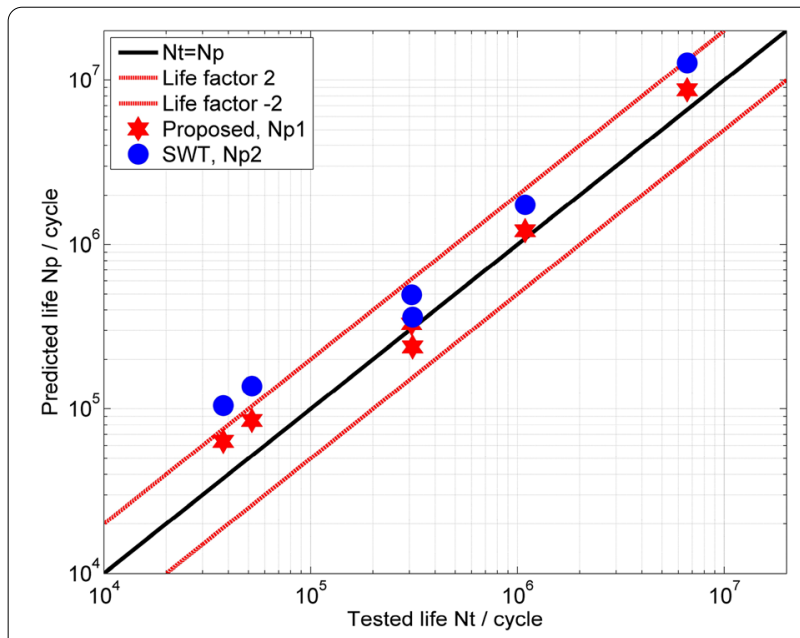

Figure 11 Predicted lives vs. tested lives of GCr15 at torsion test

mean value and the standard deviation of $P_{\text {error }}$ respectively represent the precision and concentration of the model prediction. The smaller the mean value and standard deviation, the more accurate and reliable the prediction are

$$
P_{\text {error }}=\lg \left(N_{p}\right)-\lg \left(N_{t}\right) .
$$

The prediction error of the proposed model and SWT model on the experimental data are shown in Figures 12, 13, 14 and 15. Moreover, with Eq. (26), the mean value and the standard deviation of $P_{\text {error }}$ using the two models for the three materials are depicted in Table 6 .

Overall, it is obviously seen from Table 6 that both the mean value and standard deviation of $P_{\text {error }}$ of the proposed model are the smallest among the results of SWT
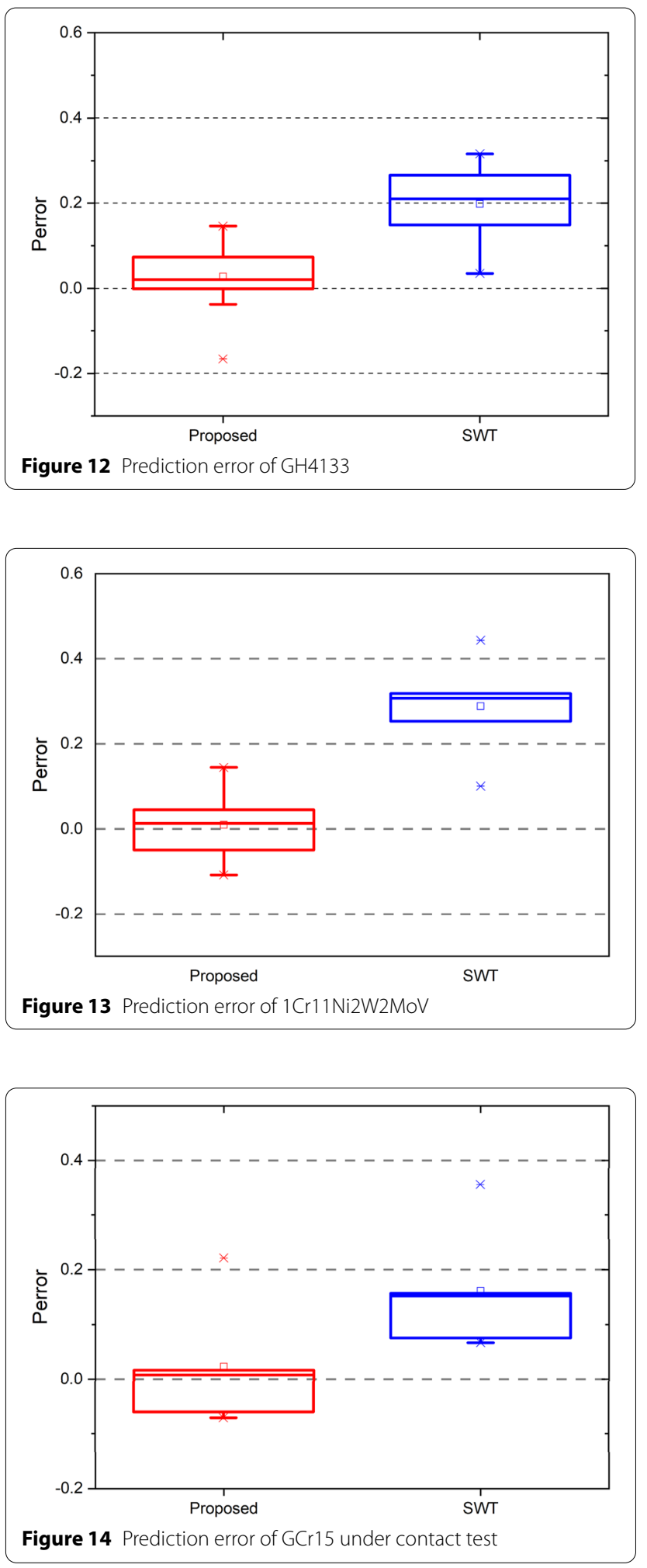


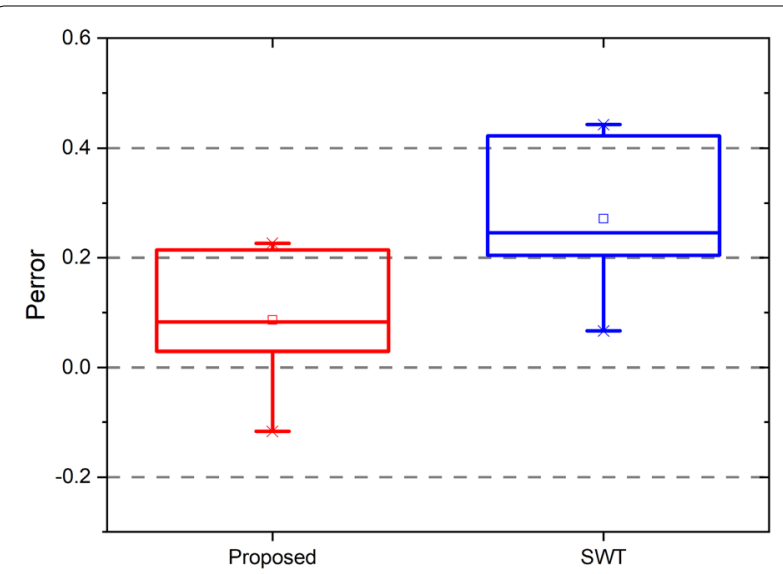

Figure 15 Prediction error of $\mathrm{GCr} 15$ under torsion test

Table 6 Statistical analysis of model prediction errors

\begin{tabular}{llll}
\hline Material & Statistical parameters & Proposed model & SWT \\
\hline \multirow{2}{*}{ Cr11Ni2W2MoV } & Mean & 0.0098 & 0.2880 \\
& Standard deviation & 0.0860 & 0.1113 \\
GH4133 & Mean & 0.0280 & 0.1976 \\
& Standard deviation & 0.0746 & 0.0758 \\
GCr15 (contact) & Mean & 0.0230 & 0.1613 \\
& Standard deviation & 0.1163 & 0.1176 \\
GCr15 (torsion) & Mean & 0.0865 & 0.2711 \\
& Standard deviation & 0.1288 & 0.1436 \\
\hline
\end{tabular}

model. This implies that the proposed model is better among the two models in predicting the fatigue life for alloys and steels.

\subsection{Life Prediction of the Proposed Model for Rolling Bearings}

In this section, a deep groove ball bearing (code 6206), made by GCr15, is used in the experiment, see Table 7 . Under the conditions of radial force of $5 \mathrm{kN}$ and a rotation speed of $12000 \mathrm{r} / \mathrm{min}$, the distribution of rolling element load is obtained through quasi-static analysis. Then, according to the Hertz contact theory, the contact stress of the rolling bearing is analyzed.

The rolling element load at different angular positions is shown in Figure 16, and the contact stress of inner raceway distribution at different angular positions is shown in Figure 17. In detail, at the current conditions, the maximum rolling element load $Q_{\max }$ is $2509 \mathrm{~N}$, the maximum contact stress of the inner raceway and the
Table 7 Specification of the tested bearing

\begin{tabular}{ll}
\hline Parameter & Value \\
\hline Ball nominal diameter $D_{b}(\mathrm{~mm})$ & 9.525 \\
Pitch diameter of the bearing $D_{m}(\mathrm{~mm})$ & 46 \\
Coefficient of inner raceway groove curvature radius $f_{i}$ & 0.515 \\
Coefficient of outer raceway groove curvature radius $f_{e}$ & 0.52 \\
Number of balls $Z$ & 9
\end{tabular}

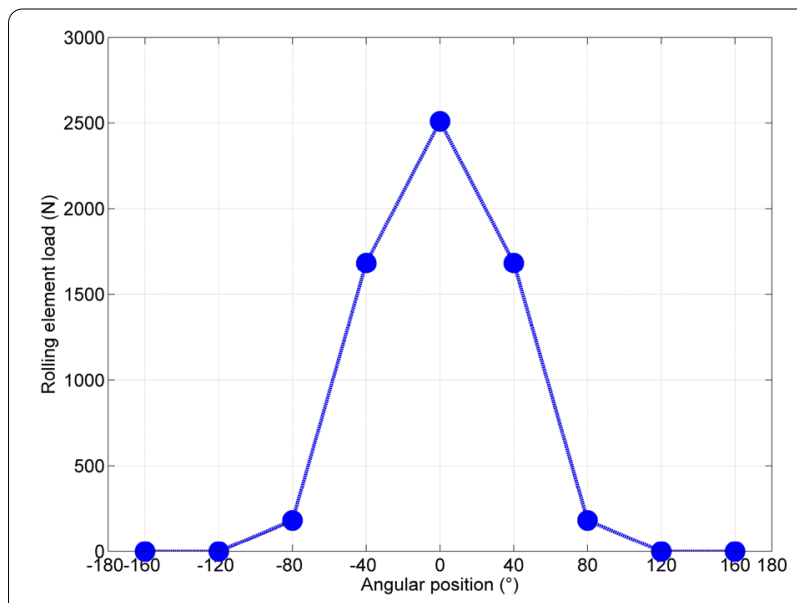

Figure 16 Rolling element load at the different angular positions

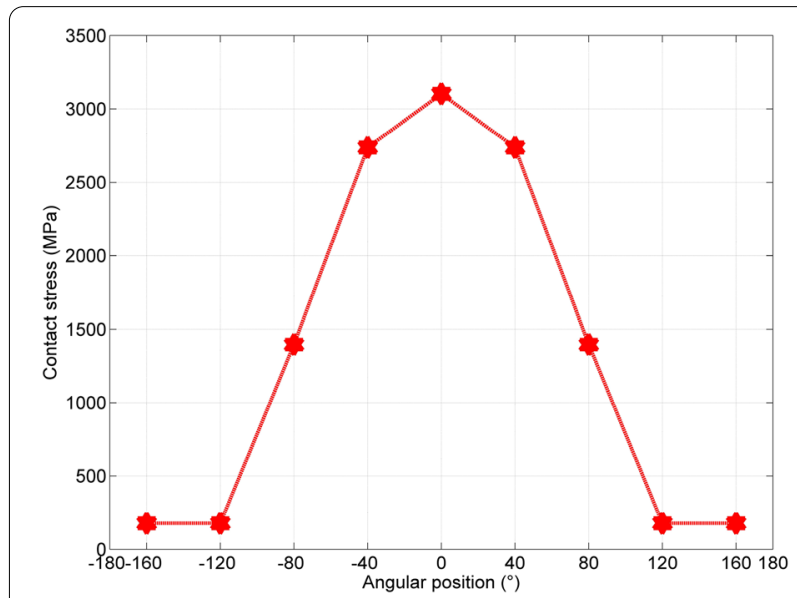

Figure 17 Contact stress distribution of inner raceway at the different angular positions

outer raceway, respectively, are $3102 \mathrm{MPa}$ and 2636 $\mathrm{MPa}$.

According to Eqs. (17)-(19), the fatigue lives of inner ring and outer ring are calculated. Finally, through Eq. (25), the predicted life of rolling bearing is obtained. 

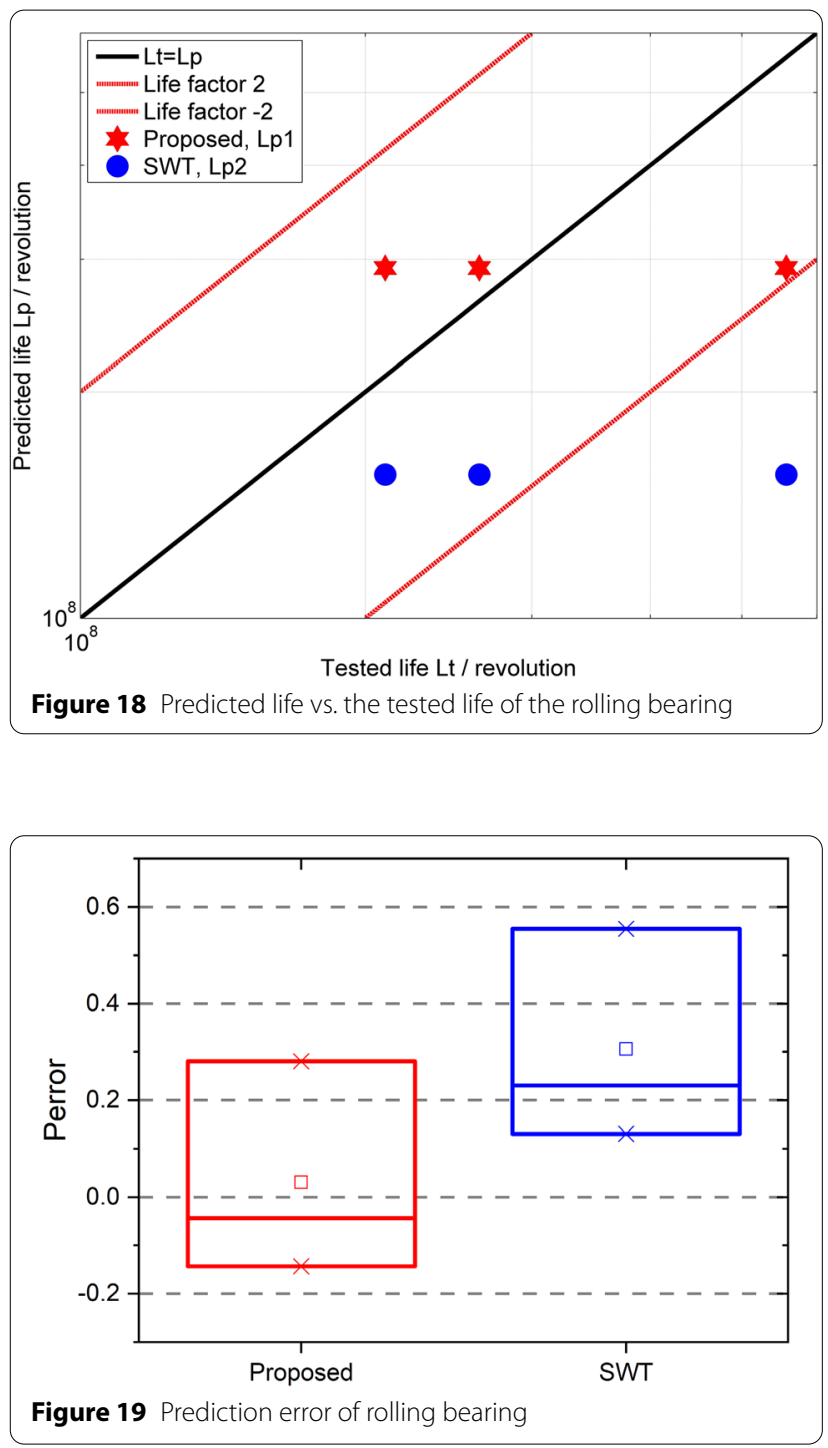

Likewise, using the proposed model and SWT model, the predicted life of the bearing is calculated and compared. The comparison between the bearing's tested lives and predicted ones derived from different models are shown in Figure 18 [49].

From Figure 18, it is worth mentioning that two predictions computed from the SWT model fall within a life factor of \pm 2 to the tested lives, and one is outside. However, all predictions of the proposed model fall within a life factor of \pm 2 to the tested lives. Similarly, a statistical analysis is conducted, and its mean value and the standard deviation of $P_{\text {error }}$ is shown in Figure 19 and Table 8.

As it can be seen in Figure 19 and Table 8, the proposed model with a smaller mean value of $P_{e r-}$ ror provides better predictions of bearing than the
Table 8 Statistical analysis of model prediction errors

\begin{tabular}{lll}
\hline Statistical parameters & Proposed model & SWT \\
\hline Mean & 0.0311 & 0.3052 \\
Standard deviation & 0.2215 & 0.2215 \\
\hline
\end{tabular}

conventional SWT model. In general, through the proposed model, the fatigue life of rolling bearings made of steels can be predicted with higher precision and simple calculation process.

\section{Conclusions}

In this paper, a modified fatigue life model based on the SWT correction that considers the mean stress effect and sensitivity is proposed to predict fatigue life of bearings. Experimental data of materials is used to verify the proposed method. The conclusions are drawn as follows:

(1) Considering the sensitivity of different materials to the mean stress, a modified model is established based on the SWT correction to estimate the fatigue life. The experimental data of three materials: GH4133, $1 \mathrm{Cr} 11 \mathrm{Ni2}$ W2MoV, and GCr15 are used for model verification. Compared with the SWT model, the applicability of the proposed model is better, and the life prediction results of the three materials are more accurate, which shows that the proposed model is suitable for life prediction of alloys and steels.

(2) Based on the proposed model, the life prediction model of rolling bearings is established. Moreover, by using the proposed model and the SWT model, the fatigue life of ball bearing is predicted under the working conditions on $5 \mathrm{kN}$ radial force and 12000 $\mathrm{r} / \mathrm{min}$, and then the predicted results are compared with the tested ones. The comparison shows that the proposed model is consistent to the experimental results, and it is feasible to apply the proposed model to the fatigue life prediction of rolling bearings.

\section{Acknowledgements}

Not applicable.

\section{Authors' contributions}

$\mathrm{HH}$ was in charge of the whole trial; $\mathrm{AY}$ wrote the manuscript; $\mathrm{YL}, \mathrm{HL}$ and $\mathrm{YZ}$ assisted with sampling and laboratory analyses. All authors read and approved the final manuscript.

\section{Authors' Information}

Aodi Yu, born in 1992, is currently a PhD candidate at School of Mechanical and Electrical Engineering, University of Electronic Science and Technology of China, China. Her main research interests include fatigue life prediction and reliability modeling and analysis. 
Hongzhong Huang, born in 1963, is a Professor and Director of the Center for System Reliability and Safety, University of Electronic Science and Technology of China, China. He has held visiting appointments at several universities in the USA, Canada and Asia. He received a PhD degree in Reliability Engineering from Shanghai Jiaotong University, China. And has published 200 journal papers and 5 books in fields of reliability engineering, optimization design, fuzzy sets theory, and product development. His main research interests include reliability design, optimization design, condition monitoring, fault diagnosis, and life prediction.

Yanfeng Li, born in 1981, is a professor at School of Mechanical and Electrical Engineering, University of Electronic Science and Technology of China, China. He received his $\mathrm{PhD}$ degree in Mechatronics Engineering from the University of Electronic Science and Technology of China. He has published over 30 peer-reviewed papers in international journals and conferences. His research interests include reliability modeling and analysis of complex systems, dynamic fault tree analysis, and Bayesian networks modeling and probabilistic inference.

He Li, born in 1990, is currently a PhD candidate at School of Mechanical and Electrical Engineering, University of Electronic Science and Technology of China, China. His main research interests are failure and risk analysis, reliability and availability estimation.

Ying Zeng, born in 1994, is a PhD candidate at School of Mechanical and Electrical Engineering, University of Electronic Science and Technology of China, China. His current research interest focuses on reliability and fault prediction of electronic products.

\section{Funding}

This study is financially supported by the National Natural Science Foundation of China (Grant No. 51875089).

\section{Competing interests}

The authors declare no competing financial interests.

\section{Author Details}

${ }^{1}$ School of Mechanical and Electrical Engineering, University of Electronic Science and Technology of China, Chengdu 611731, China. ${ }^{2}$ Center for System Reliability and Safety, University of Electronic Science and Technology of China, Chengdu 611731, China.

Received: 15 December 2020 Revised: 17 September 2021 Accepted: 18 October 2021

Published online: 20 November 2021

\section{References}

[1] J Guo, Y F Li, Z Bo, et al. Bayesian degradation assessment of CNC machine tools considering unit non-homogeneity. Journal of Mechanical Science and Technology, 2018, 32(6): 2479-2485.

[2] J Guo, H. Zheng, B Li, et al. A Bayesian approach for degradation analysis with individual differences, IEEE Access, 2019, 7: 175033-175040.

[3] H Li, A P Teixeira, C G Soares. A two-stage failure mode and effect analysis of offshore wind turbines. Renewable Energy, 2020, 162: 1438-1461.

[4] H Li, C G Soares, H Z Huang. Reliability analysis of a floating offshore wind turbine using Bayesian networks. Ocean Engineering, 2020, 217: 107827.

[5] H M Qian, Y F Li, H Z Huang. Time-variant reliability analysis for industrial robot RV reducer under multiple failure modes using Kriging model. Reliability Engineering and System Safety, 2020, 199: 106936.

[6] P Huang, $\mathrm{HZ}$ Huang, Y F Li, et al. Positioning accuracy reliability analysis of industrial robot based on differential kinematics and saddlepoint approximation. Mechanism and Machine Theory, 2021, 162: 104367.

[7] G Lundberg, A Palmgren. Dynamic capacity of roller bearings. Acta Polytech. Scand., Mech. Eng. Ser., 1952, 2(4): 96-127.

[8] E loannides, T A Harris. A new fatigue life model for rolling bearings. Journal of Tribology, 1985, 107(3): 367-377.

[9] E V Zaretsky. Design for life, plan for death. Machine Design, 1994, 66(15): 55-59.

[10] S W Hong, V C Tong. Rolling-element bearing modeling: A review. International Journal of Precision Engineering \& Manufacturing, 2016, 17(12): 1729-1749.
[11] M Yakout, A Elkhatib, M G A Nassef. Rolling element bearings absolute life prediction using modal analysis. Journal of Mechanical Science and Technology, 2018, 32(1): 91-99.

[12] D Wang, K L Tsui. Two novel mixed effects models for prognostics of rolling element bearings. Mechanical Systems \& Signal Processing, 2018, 99: 1-13.

[13] L Cui, X Wang, Y Xu, et al. A novel switching unscented Kalman filter method for remaining useful life prediction of rolling bearing. Measurement, 2019, 135: 678-684.

[14] W Ahmad, S A Khan, M M M Islam, et al. A reliable technique for remaining useful life estimation of rolling element bearings using dynamic regression models. Reliability Engineering \& System Safety, 2018,184: 67-76.

[15] H Wang, J Chen, J Qu, et al. A new approach for safety life prediction of industrial rolling bearing based on state recognition and similarity analysis. Safety Science, 2020, 122: 104530.

[16] B Warda, A Chudzik. Fatigue life prediction of the radial roller bearing with the correction of roller generators. International Journal of Mechanical Sciences, 2014, 9: 299-310.

[17] X Shi, L Wang, F Qin. Relative fatigue life prediction of high-speed and heavy-load ball bearing based on surface texture. Tribology International, 2016, 101: 364-374.

[18] L Yang, T Xu, H Xu, et al. Mechanical behavior of double-row tapered roller bearing under combined external loads and angular misalignment. International Journal of Mechanical Sciences, 2018, 142-143: 561-574.

[19] L Quagliato, D Kim, N Lee, et al. Run-out based crossed roller bearing life prediction by utilization of accelerated testing approach and FE numerical models. International Journal of Mechanical Sciences, 2017, 130: 99-110.

[20] P He, R Hong, $\mathrm{H}$ Wang, et al. Fatigue life analysis of slewing bearings in wind turbines. International Journal of Fatigue, 2018, 111:233-242.

[21] P He, R Hong, H Wang, et al. Calculation analysis of yaw bearings with a hardened raceway. International Journal of Mechanical Sciences, 2018, 144: 540-552.

[22] R Burger, Y L Lee. Assessment of the mean-stress sensitivity factor method in stress-life fatigue predictions. Journal of Testing and Evaluation, 2013, 41(2): 200-206.

[23] Y Choi, D J Oh, J M Lee, et al. A new model of fatigue crack growth rate considering mean stress effects due to locked-in stress. International Journal of Steel Structures, 2019, 19(4): 1099-1111.

[24] A Nourian-Avval, A Fatemi. Fatigue design with high pressure die cast aluminum including the effects of defects, section size, stress gradient, and mean stress. Materials Today Communications, 2020, 25: 101567.

[25] Y Liu, M Paggi, B Gong, et al. A unified mean stress correction model for fatigue thresholds prediction of metals. Engineering Fracture Mechanics, 2020, 223: 106787.

[26] A Ince. A mean stress correction model for tensile and compressive mean stress fatigue loadings. Fatigue \& Fracture of Engineering Materials \& Structures, 2017, 40(6): 939-948.

[27] H Li, H Z Huang, Y F Li, et al. Physics of failure-based reliability prediction of turbine blades using multi-source information fusion. Applied Soft Computing, 2018, 72: 624-635.

[28] J F Barbosa, J A F O Correia, R C S F Júnior, et al. Fatigue life prediction of metallic materials considering mean stress effects by means of an artificial neural network. International Journal of Fatigue, 2020, 135: 105527.

[29] Q Zhang, X Hu, Z Zhang, et al. The mean stress and phase angle effect on multiaxial fatigue behavior of a TiAl alloy: failure analysis and life modeling. International Journal of Mechanical Sciences, 2020: 106123.

[30] M Benedetti, F Berto, L L Bone, et al. A novel strain-energy-density based fatigue criterion accounting for mean stress and plasticity effects on the medium-to-high-cycle uniaxial fatigue strength of plain and notched components. International Journal of Fatigue, 2020, 133: 105397.1-105397.19.

[31] R B Kalombo, M S Pestana, R C S F Júnior, et al. Fatigue life estimation of an all aluminium alloy 1055 MCM conductor for different mean stresses using an artificial neural network. International Journal of Fatigue, 2020, 140: 105814.

[32] T Li, S A Nassar, M El-Zein. Novel model for mean stress effect on highcycle fatigue performance of threaded fasteners. Journal of Advanced Joining Processes, 2020, 1: 100004. 
[33] T Laszlo, K Laszlo, O Tamas. Numerical tool with mean-stress correction for fatigue life estimation of composite plates. Engineering Failure Analysis, 2020, 111: 104456.

[34] Y C Duan, F F Zhang, D Yao, et al. Numerical prediction of fatigue life of an A356-T6 alloy wheel considering the influence of casting defect and mean stress. Engineering Failure Analysis, 2020, 118: 104903.

[35] B Allison, A Pandkar. Critical factors for determining a first estimate of fatigue limit of bearing steels. International Journal of Fatigue, 2018, 117: 396-406.

[36] S Hashimoto, H Komata, S Okazaki, et al. Quantitative evaluation of the flaking strength of rolling bearings with small defects as a crack problem. International Journal of Fatigue, 2019, 119: 195-203.

[37] X L Zheng, H Wang, J H Tan, et al. Yi. Material fatigue theory and engineering application. Beijing: Science Press, 2013. (in Chinese)

[38] J A R Duran, CT Hernandez. Evaluation of three current methods for including the mean stress effect in fatigue crack growth rate prediction. Fatigue \& Fracture of Engineering Materials \& Structures, 2015, 38(4): 410-419.

[39] K N Smith, P Watson, T H Topper. A stress-strain function for the fatigue of materials. Journal of Materials, 1970, 5: 767-778.

[40] N E Dowling, C A Calhoun, A Arcari. Mean stress effects in stress-life fatigue and the Walker equation. Fatigue \& Fracture of Engineering Materials \& Structures, 2009, 32(3): 163-179.

[41] T Nagatomo, KTakahashi, Y Okamura, et al. Effects of load distribution on life of radial roller bearings. Journal of Tribology-Transactions of The ASME, 2012, 134(2): 021101
[42] W Guo, H Cao, Z He, et al. Fatigue life analysis of rolling bearings based on quasistatic modeling. Shock and Vibration, 2015: 1-10.

[43] Z J Liu, S Q He, H Liu. Rolling bearing applications. Beijing: China Machine Press, 2007. (in Chinese)

[44] W G Wang. Research on prediction model for disc LCF life and experiment assessment methodology. Nanjing: Nanjing University of Aeronautics and Astronautics, 2006.

[45] Y Gao, H Han, X Zhang. Measurement of contact fatigue P-S-N curve for specially strengthened GCr15 steel balls. Bearing, 2005, 8: 30-31. (in (hinese)

[46] S Shimizu, K Tsuchiya, K Tosha. Probabilistic stress-life (p-s-n) study on bearing steel using alternating torsion life test. Tribology Transactions, 2009, 52(6): 807-816.

[47] S Zhu, Q Lei, H Huang, et al. Mean stress effect correction in strain energybased fatigue life prediction of metals. International Journal of Damage Mechanics, 2016, 26(8): 1219-1241.

[48] S Zhu, Q Lei, Q Wang. Mean stress and ratcheting corrections in fatigue life prediction of metals. Fatigue \& Fracture of Engineering Materials \& Structures, 2017, 40(9): 1343-1354.

[49] Y Zhang, G Chen, J Xie, et al. Damage mechanics-finite element method for contact fatigue life prediction of ball bearings. Journal of Aerospace Power, 2019, 34(10): 2246-2255.

\section{Submit your manuscript to a SpringerOpen ${ }^{\odot}$ journal and benefit from:}

- Convenient online submission

- Rigorous peer review

- Open access: articles freely available online

- High visibility within the field

- Retaining the copyright to your article

Submit your next manuscript at $\mathbf{s p r i n g e r o p e n . c o m ~}$ 